\title{
PERANCANGAN DAN IMPLEMENTASI WEB FORUM ALUMNI UNIVERSITAS INTERNASIONAL BATAM
}

\author{
Heru Wijayanto Aripradono, Kelvin \\ Universitas Internasional Batam \\ heru.wijayanto@uib.ac.id
}

\begin{abstract}
Abstrak
Perkembangan teknologi informasi, khususnya internet saat ini, sudah masuk dalam berbagai bidang kehidupan manusia, diantaranya dalam dunia pendidikan tinggi terutama untuk membangun kolaborasi antar pengguna dalam dunia digital. Penelitian bertujuan untuk membuat sebuah website forum alumni yang merupakan platform bagi pihak universitas dan alumni untuk dapat membagi informasi dan komuniasi. Dalam web forum alumni tersebut tersebut akan ada fitur seperti Chatroom, discussion, list alumni dan Map. Pada proses perancangan proyek ini bahasa pemograman PHP dengan framework Laravel, kemudian menggunakan HTML dan BootStrap yang digunakan dalam perancangan tampilan website tersebut. Adapun database yang digunakan adalah MySQL. Penggunaan Forum Alumni di Universitas International Batam sangatlah membantu pihak universitas maupun alumni dimana mereka dapat saling membagi informasi dan menjalin komunikasi.
\end{abstract}

Kata kunci: Web, Forum Alumni, Universitas, Platform

\begin{abstract}
The development of information technology, especially in the internet today, has entered various fields of human life, including in the world of higher education, especially to build collaboration between users in the digital world. The research aims to create an alumni forum website which is a platform for universities and alumni to be able to share information and communication. In the alumni web forum there will be features such as chatrooms, discussions, alumni lists and maps. In the process of designing this project the PHP programming language with the Laravel framework, then uses HTML and BootStrap which are used in designing the appearance of the website. The database used is MySQL. The use of the Alumni Forum at Batam International University is very helpful for the university and alumni where they can share information with each other and establish communication.
\end{abstract}

Keywords : Web, Forum Alumnae, University, Platform

\section{PENDAHULUAN}

Perkembangan teknologi informasi, khususnya internet saat ini, sudah masuk dalam berbagai bidang kehidupan manusia, diantaranya dalam membangun kolaborasi antar pengguna dalam dunia digital. Perubahan teknologi informasi itu sendiri telah memungkinkan penggunaan aplikasi web baru yang dinamis dan sering disebut sebagai aplikasi web 2.0, dimana dalam teknologi ini memungkinkan pengguna untuk berkolaborasi dan berbagi konten secara online, mengubah peran pengguna dari konsumen pasif konten menjadi pembuat konten (1). Kehadiran teknologi tersebut, membuat beberapa organisasi mulai melakukan adopsi penggunaan teknologi Web 2.0, seperti seperti blog, jejaring sosial, forum internet, kalender, wiki, podcast, aplikasi pemesanan, layanan berbagi file dan tagging, hal ini menyebabkan meningkatnya kebutuhan organisasi dalam melakukan hubungan dan kolaborasi dengan pasar mereka $(2,3)$. Dinamika perkembangan dari teknologi

http://ejournal.urindo.ac.id/index.php/TI 
Web 2.0 itu sendiri telah menghasilkan sebuah hubungan interaktif dalam internet, yang tentu saja dibutuhkan kontribusi para penggunanya, sehingga dampak yang dihasilkan dari kolaborasi dan kontribusi tersebut dapat menjadi lebih maksimal (4).

Indonesia sendiri termasuk ke dalam negara yang cukup tinggi dalam hal penggunaan teknologi web 2.0, dimana angkanya mencapai $65,1 \%$ (diatas angka rata-rata dunia, yaitu $44,8 \%$ ) dari keseluruhan pengguna internet di Indonesia (5). Hal inilah yang digunakan oleh para organisasi untuk menggunakan platform tersebut dalam membangun keterlibatan dan hubungan dengan para stakeholdernya $(6,7)$. Tak terkecuali dengan institusi pendidikan tinggi, dimana salah satu yang dapat dimanfaatkan adalah web forum internet dalam membangun komunikasi dan keterlibatan kontribusi positif dengan para mahasiswa dan alumninya untuk tujuan proses dalam pendidikan (8).

Institusi pendidikan tinggi saat ini mulai mengandalkan berbagai platform teknologi web 2.0, seperti media sosial, forum, blog dan lainnya, karena hal ini adalah salah satu pendekatan yang efisien, mudah dan murah, terutama untuk mengatasi berbagai macam tantangan yang ada, seperti bagaimana membangun keterlibatan dan juga membangun kesadaran dengan para pengguna dan stakeholdernya (9). Institusi Pendidikan Tinggi juga menggunakan platform tersebut untuk melibatkan keterlibatan dan membina hubungan dengan para pemangku kepentingan, dalam hal ini para civitas academika, stakeholder dan juga para calon mahasiswa termasuk juga dalam membina keberlanjutan kedepannya (10).

Forum merupakan platform yang digunakan untuk menukar informasi diskusi ataupun pertemuan untuk menemukan solusi dari sebuah masalah (11). Forum ini memiliki banyak peran yang dapat digunakan oleh organisasi, mulai dari pertukaran info antar sesame seperti ilmu pengetahuan, lamaran kerja, kegiatan sosial, ataupun sumbangan ke organisasi. Penggunaan forum sangatlah berperan penting untuk mengumpulkan informasi misalnya forum alumni yang di buat untuk menghubungkan para mahasiswa yang sudah lulus agar tetap menjalin hubungakn komunikasi yang baik, serta tetap dapat membagikan pengetahuan antar pengguna, seperti kegiatan universitas, lowongan pekerjaan, ataupun informasi lainnya (12).

Forum alumni adalah platform yang berbasis web yang dimana menyediakan tempat bagi alumni untuk meyambungkan hub antar alumni, menjadi sarana tukar pikiran antar satu dengan yang lain agar mempertahankan keharmonisan antar alumni (13). Forum alumni merupakan bagian dari sistem informasi yang dapat di temukan pada lingkungan pendidikan seperti sekolah maupun perguruan tinggi. Selain untuk menyambung dan sarana tukar pikiran forum alumni ini sangatlah berguna untuk penggunanya seperti universitas dapat mencari alumni-alumni dengan menggunakan forum tersebut dan memberikan informasi-informasi.

Universitas Internasional Batam (UIB) merupakan universitas internasional yang berdiri pada tahun 2000 berdasarkan keputusan Menteri Pendidikan Nasional Republik Indonesia No. 160/D/O/2000, yang merupakan salah satu bentuk kepedulian Yayasan Marga Tionghoa Indonesia (YMTI) di Kota Batam terhadap pendidikan masyarakat khususnya di Pulau Batam dan sekitarnya. Sebagai salah satu kampus internasional UIB tentunya memiliki banyak kerja sama dengan berbagai universitas di luar negeri, seperti Taiwan, Malaysia, Jepang, Korea Selatan, China dan beberapa negara lainnya.

Dengan banyaknya kerja sama internasional tersebut menyebabkan banyak juga mahasiswa yang mengambil kesempatan tersebut untuk melanjutkan perkuliahan mereka di luar negeri, terutama dengan kampus yang bekerjasama dengan UIB itu sendiri. Namun dikarenakan kurangnya wadah komunikasi antara perguruan tinggi dengan mahasiswa dan alumni itu sendiri sehingga terjadi kehilangan komunikasi yang membuat perguruan tinggi sendiri tidak dapat mengetahui perkembangan dari alumni tersebut. Alumni merupakan sebuat aset yang sangat penting bagi perguruan tinggi, dimana alumni dapat berperan besar dalam memberikan 
masukan yang membangun kepada perguruan tinggi dan juga meningkatkan jaringan kerjasama serta kolaborasi. Oleh karena itu, adanya sebuah kebutuhan untuk merancang dan membuat aplikasi berbasis web untuk mempermudah dalam proses komunikasi antar alumni dengan pihak universitas. Selain proses komunikasi antar alumni dengan pihak universitas, para alumni juga dapat membagikan informasi-informasi yang saling mengguntungkan antar sesama alumni itu sendiri.

Berdasarkan hal tersebut, maka diperlukan wadah yang dapat dipergunakan oleh alumni agar dapat berkomunikasi dan saling berbagi, yang dimana penulis akan merancang sebuah wadah yaitu berupa forum alumni yang dapat diakses oleh para alumni UIB, dan akan digunakan membagikan informasi dan membangun komunikasi antar UIB dan alumni ataupun antar jejaring alumni UIB itu sendiri.

\section{METODE}

Metode yang digunakan dalam proses perancangan dan implementasi Web Forum Alumni di UIB, terdiri dari beberapa tahapan penerapan. Pada tahap awal yaitu akan dilakukan tahapan pengumpulan data, dimana pada tahap awal ini penulis melakukan pengumpulan data dengan melakukan wawancara terhadap beberapa pihak yang terlibat dan berinteraksi dalam proses ini. Pada tahap ini juga akan dilakukan observasi mengenai bagaimana para alumni saling membagikan informasi dan komunikasi baik antar alumni ataupun dengan pihak universitas Tujuan dari observasi ini adalah untuk memastikan fitur yang di rancang nanti nya dalam platform web alumni.

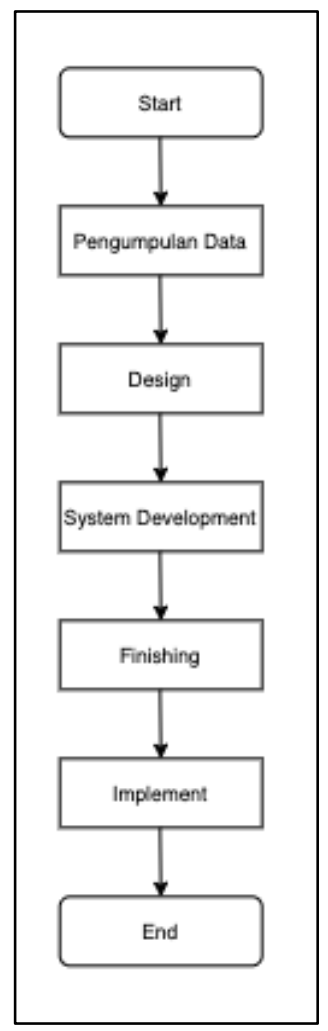

\section{Gambar 1. Tahapan Perancangan Web Forum Alumni}

Tahap berikutnya yaitu tahapan perancangan atau design, dimana dalam tahapan ini akan dilakukan pembuatan desain mengenai gambaran tentang bentuk web yang akan di rancang. Pada tahapan ini design yang di buat berupa tampilan dari website dan posisi dari fitur fitur yang akan di tampilkan dalam website tersebut. Penulis menggunakan CSS dan Bootstrap dalam pembuatan design User interface.

Kemudian akan dilanjutkan dengan tahapan yang ketiga yaitu System Development, dimana dalam tahapan ini akan dilakukan pengembangan website forum alumni menggunakan PHP dengan framework Laravel. Laravel merupakan framework bahasa pemograman Hypertext Preprocessor (PHP) yang dimana Model view Controller (MVC) merupakan konsep yang di terapkan dalam pegembangan aplikasi web. Fungsi menggunakan framework tersebut adalah agar proses pengembangan website lebih cepat, tampilan website akan lebih dinamis, dan framework tersebut memiliki system perlindungan data yang sangat baik. Pada tahap 
akhir akan dilakukan pengujian secara keseluruhan terhadap system website yang telah di buat agar tidak ada kesalahan atau pun masalah saat di implementasikan.

\section{HASIL DAN PEMBAHASAN}

\section{PENGUMPULAN DATA}

Hasil penggumpulan data yang telah di lakukan didapatkan bahwa UIB sendiri belum mempunyai Forum Alumni yang dimana akan mempermudah atau menjadi solusi untuk masalah yang sedang di hadapi UIB sekarang. Selain itu dalam wawancara tersebut terdapat beberapa fitur-fitur tambahan yang diajukan yaitu Peta yang di mana bertujuan untuk pihak Universitas dapat mengetahui posisi dari alumni mereka dan LiveChat room tujuan dari fitur tersebut adalah agar para alumni dapat membagi atau berkomunikasi secara private.

\section{PERANGKAT KERAS DAN LUNAK}

Perangkat keras yang digunakan dalam mengimplementasikan web forum alumni ini adalah processor i5-5200U CPU @ 2.20GHz (4CPus), Ram 8GB dan Solid State Drive 512GB dan beberapa perangkat tambahan seperti Keyboard, mouse dan monitor. Spesifikasi minimum untuk server adalah $\mathrm{CPU} 1 \mathrm{GHz}$, Ram $2 \mathrm{~Gb}$ dan harddisk $10 \mathrm{~Gb}$ ini merupakan spesifikasi untuk hosting website forum alumni pada proyek ini.

Perangkat lunak yang digunakan dalam pengembangan proyek ini framework Laravel, Google Chrome, Visual Code, Xampp, MySQL dan juga menggunakan sistem operasi Windows 10 Pro.

\section{PERANCANGAN SYSTEMS}

Pada database untuk perancangan dan implementasi web alumni ini terdapat relasi antar model yang di susun pada database yang akan digunakan dalam platform ini. Berdasarkan gambar 1 dapat di lihat terdapat pengguna yang memiliki role berbeda yaitu admin dan alumni. Setiap pengguna dapat membuat discussion dengan relasi one to many, dimana pada saat membuat topik diskusi akan di kelompokkan berdasarkan kategori yang dibuat sehingga relasi discussion dengan categories adalah one to one.
Antar pengguna dapat menggunakan chat room, dimana relasi pengguna dengan messages adalah one to many dan relasi messages dengan pengguna adalah many to one, dengan kata lain pengguna dapat mengirim banyak messenger ke pengguna lain dan hanya satu pengguna yang dapat menerima messages yang di kirim. Tiap pengguna akan mendapatkan notifikasi jika ada yang melakukan reply pada discussion yang di buat atau pun discussion yang di reply.

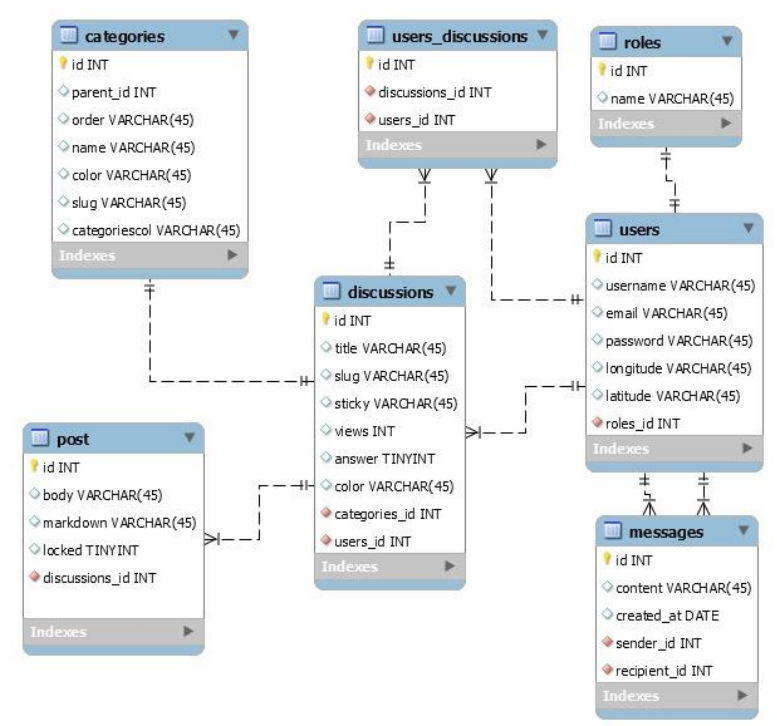

Gambar 2. Entity Relationship Diagram

Dalam Use case diagram pada gambar 2, akan menjelaskan apa saja yang bisa di lakukan oleh pengguna pada saat menggunakan Forum tersebut. Pengguna dapat membuat diskusi baru dan juga dapat melakukan interaksi didalam diskusi dengan melakukan komentar pada diskusi tersebut, pengguna alumni juga dapat melihat posisi dimana saja para alumni berada seperti di Negara Jepang ada berapa alumni dan sebagainya, selain dari itu pengguna alumni juga dapat melakukan private chat antar alumni maupun dengan pihak universitas karena tersedia nya ruang chat. Pada pengguna admin yang akan di pegang oleh pihak universitas, user tersebut dapat melakukan hal yang sama dengan pengguna alumni yang dimana admin dapat membuat diskusi baru maupun melakukan komentar pada diskusi tersebut, dapat melakukan chat privasi pada ruang chat dan juga dapat melihat posisi para alumni mereka. Selain dari itu pengguna admin memiliki kelebihan yang dimana admin dapat menghapus diskusi yang

http://ejournal.urindo.ac.id/index.php/TI 
tidak pantas seperti pornografi maupun kata-kata kotor.

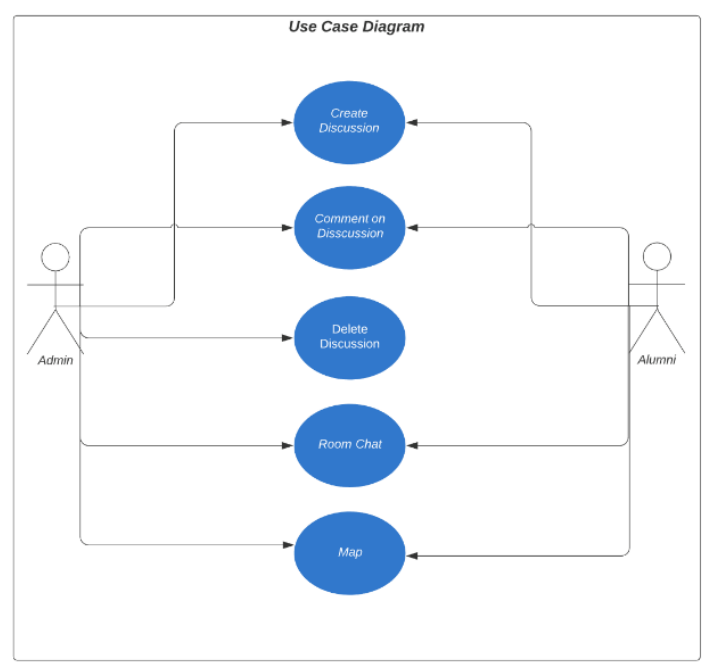

Gambar 3. Use Case Diagram

\section{IMPLEMENTASI SISTEM}

Dashboard adalah halaman pertama ketika pengguna website menulusuri website tersebut, seperti yang ditampilkan pada gambar 3. Pada tampilan ini para pengunjung dapat melihat semua topik yang telat dibuat akan tetapi mereka tidak dapat membuat topik dan komentar jika mereka tidak memiliki akun pengguna.

Pada halaman Login, seperti yang ditampilkan dalam gambar 4, adalah merupakan tampilan di mana pengguna dapat melakukan pengenalan identitas yang dimana memerlukan username atau email dan password agar dapat menggunakan sistem forum web alumni tersebut.

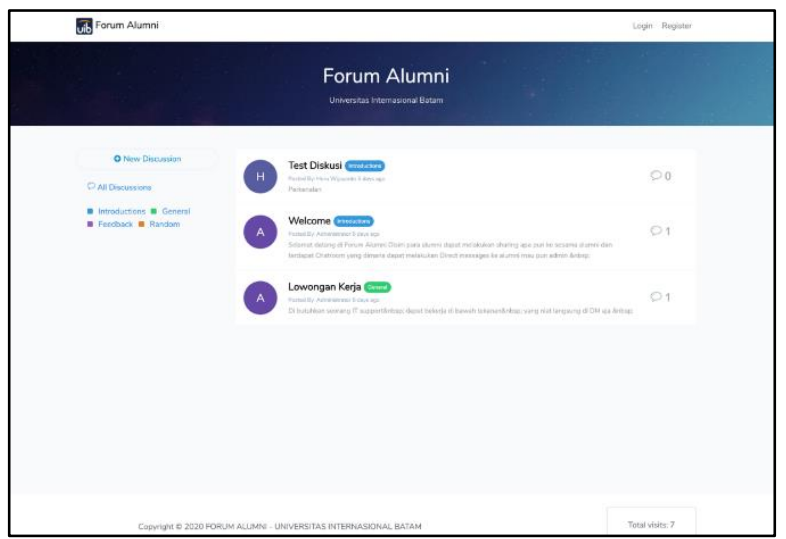

Gambar 4. Halaman Dashboard Web Forum Alumni

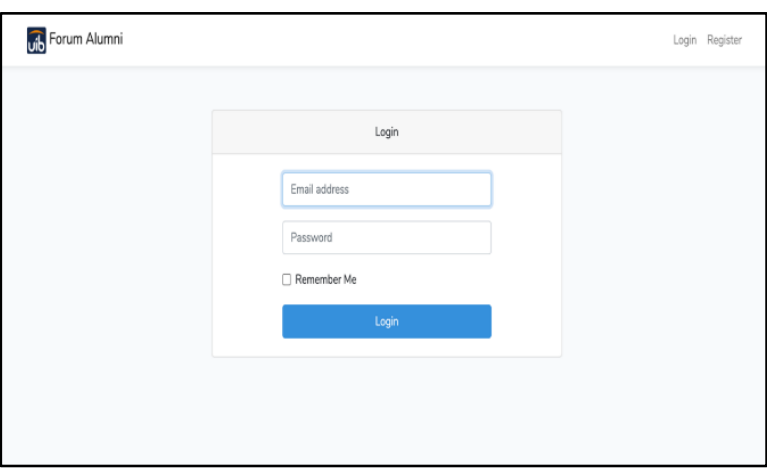

Gambar 5. Halaman Login Web Forum Alumni

Halaman registrasi merupakan halaman dimana pengguna dapat melakukan pendaftaran dengan melakukan pengisian pada semua kolom-kolom informasi yang diperlukan agar dapat menggunakan sistem website tersebut.

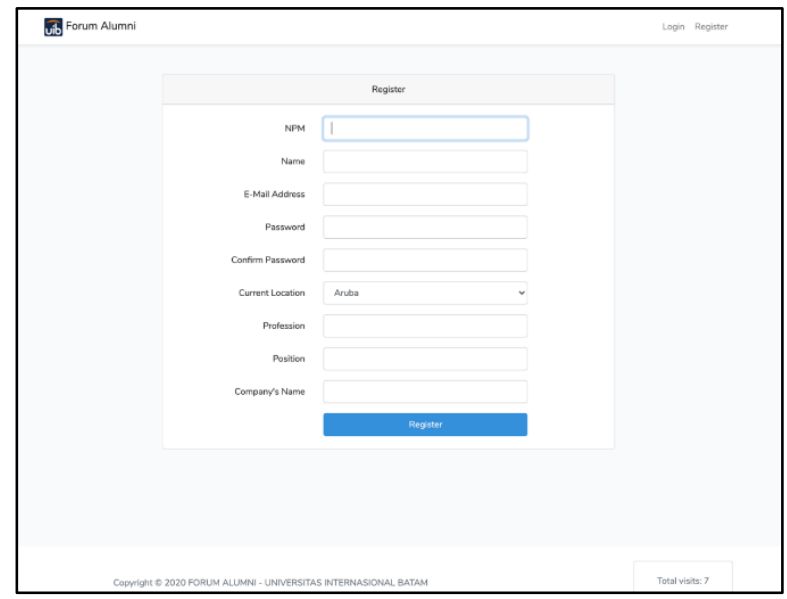

Gambar 6. Halaman Registrasi Web Forum Alumni

Pada halaman admin dahsboard ini murupakan halaman utama pada admin yang memiliki fitur discussion feed, create discussion, fitur peta, chatroom dan list alumni. Untuk fitur list alumni merupakan fitur yang hanya ada pada admin saja yang bertujuan bagi admin untuk dapat melihat informasi daftar alumni. 


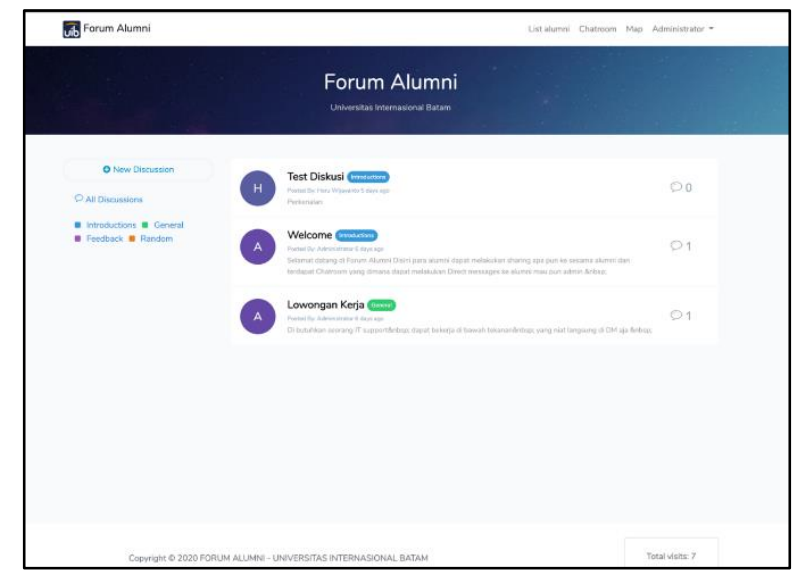

Gambar 7. Halaman Admin Dashboard

Pada halaman list alumni ini merupakan fitur yang dimiliki pengguna admin, dimana admin dapat melihat informasi-informasi alumni seperti nama, email, lokasi, profesi, posisi atau jabatan pekerjaan dan Tempat bekerja. Pada fitur ini admin juga dapat mengaktifkan dan menonaktifkan id alumni.

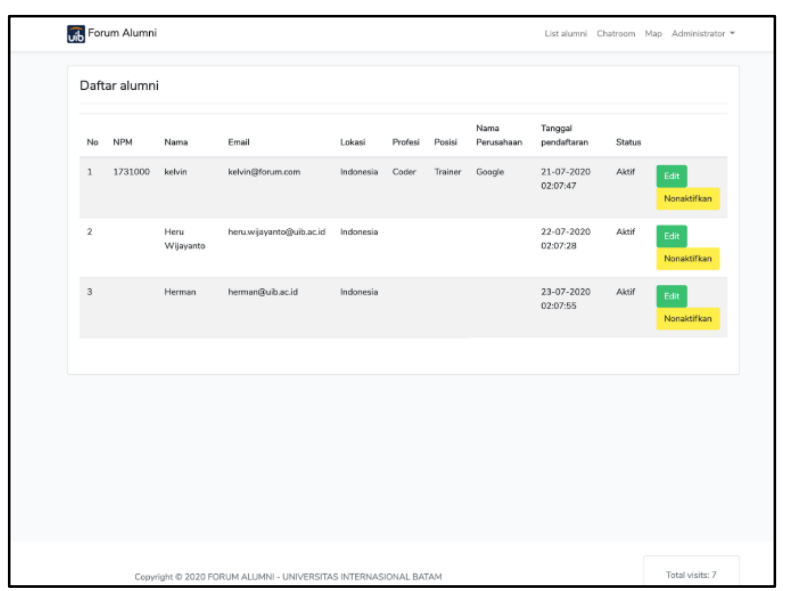

Gambar 8. Halaman List Alumni

Halaman Chat Room, seperti yang ditampilkan pada gambar 9, ini merupakan fitur yang dimana para pengguna maupun admin dapat melakukan komunikasi antar sesama secara private. Halaman Map (gambar 9) merupakan fitur dimana menampilkan persebaran seluruh alumni UIB yang terdaftar aktif di forum tersebut. Dengan adanya fitur ini, maka pihak universitas dapat mengetahui pemetaan dan penyebaran lokasi (baik yang berada di dalam negeri ataupun yang berada di luar negeri) dari para alumni UIB.

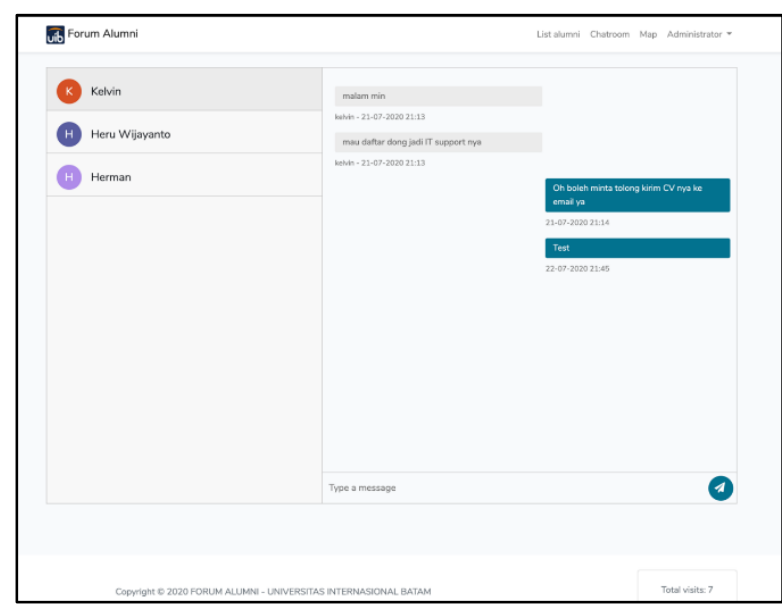

Gambar 9. Halaman Chat Room

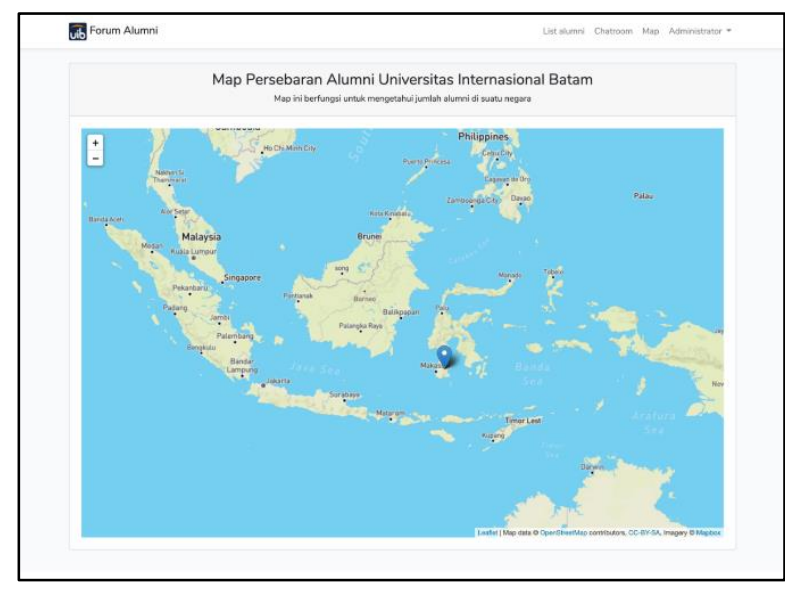

Gambar 10. Halaman Peta Penyebaran Alumni

Pada halaman ini digunakan oleh pengguna maupun admin dalam membuat topik pada forum untuk di diskusikan ataupun untuk membagi informasi antar sesama alumni. Dengan adanya forum diskusi ini, maka antar pengguna dapat saling bertukar informasi satu sama lain, atau pun saling diskusi yang membangun, misalnya terkait dengan masukan ataupun pengembangan universitas kedepannya.

Dalam proses diskusi, tetap dilakukan pemantauan oleh admin, terkait dengan topik dan juga hal-hal yang didiskusikan. Hal ini diperlukan untuk menjaga agak diskusi yang dilakukan, bukan merupakan diskusi yang mengarah ke arah negatif ataupun diskusi mengenai hal -hal yang berkaitan dengan politik atau SARA. 


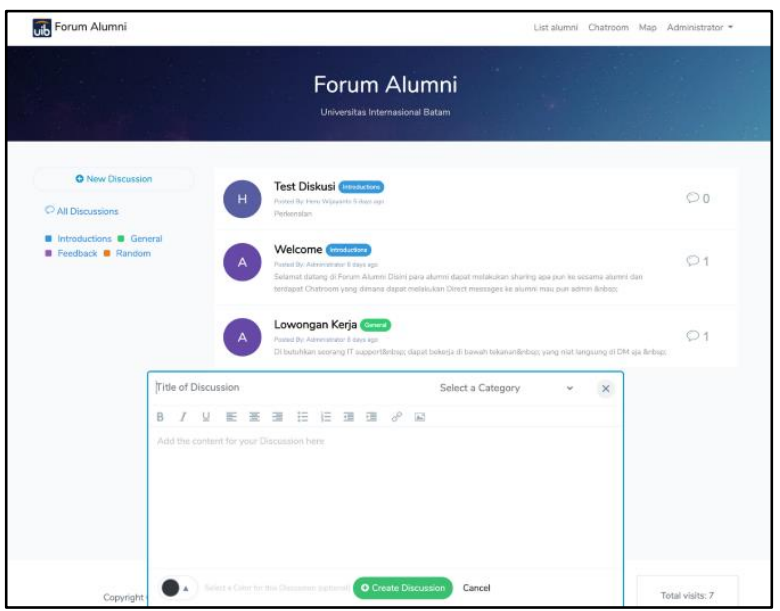

Gambar 11. Halaman Create Discussion

Penggunaan Forum Alumni di Universitas International Batam sangatlah membantu pihak universitas maupun alumni dimana mereka dapat saling membagi informasi dan menjalin komunikasi. Penggunaan list alumni sangat membantu pihak universitas dalam mengumpulkan data alumni, terutama untuk mendapatkan testimoni dan proses tracer study. Selain dari itu ada beberapa informasi yang sangat membantu alumni yaitu informasi lowongan perkerjaan, dimana pada forum ini pihak universitas dan alumni juga dapat membagikan informasi tentang lowongan kerja di tempat mereka kerja maupun informasi lowongan kerja yang tersedia lainnya.

\section{KESIMPULAN}

Website forum alumni Universitas International Batam berjalan dengan lancar dan berdasarkan hasil diskusi, mendapatkan respon positif dan mampu membantu para alumni maupun pihak Universitas, dalam menjawab permasalahan yang selama ini dihadapi terutama terkait dengan kebutuhan dalam komunikasi antara pihak universitas dan alumni.

Berdasarkan hasil implementasi yang telah dilakukan, sudah sejalan dengan tujuan dari penelitian ini yaitu untuk membantu pihak Universitas agar dapat lebih mudah untuk berinteraksi dengan alumni dan membagi informasi-informasi penting, selain dari itu para alumni juga dapat mendapatkan informasi- informasi penting, seperti lowongan kerja, beasiswa ataupun informasi lainnya.

Dalam proses pengembangan proyek ini ada beberapa saran yang diberikan oleh pihak universitas agar dapat dikembangkan kedepannya, sehingga mampu meningkatkan kualitas yang diharapkan, seperti

1. Menambahkan informasi-informasi seperti profesi, jabatan dan tempat bekerja alumni tersebut.

2. Beberapa perbaikan dari design yang di anggap kurang tepat seperti tinggi dari chat field, scroll bar list alumni yang disembunyikan dan juga penambahan footer.

3. Menambahkan statistic pengunjung web forum tersebut tersebut.

Berdasarkan saran yang telah di berikan penulis alam melakukan sesuai dengan saran sehingga web forum alumni tersebut dapat berfungsi dengan semaksimal dan dapat membantu pihak universitas untuk menyelesaikan permasalahan yang di hadapi. Untuk pengembanggan ke depan nya akan di buat map yang lebih spesifik ke kota mana saja penyebarannya dan akan di kembangkan dalam bentu mobile apps.

\section{DAFTAR PUSTAKA}

1. Valacich J, Schneider C. Information System Today: Managing In The Digital World. Eight Edit. New York: Pearson Education, Inc; 2018.

2. Hvass KA, Munar AM. The takeoff of social media in tourism. J Vacat Mark. 2012;

3. Zeng B. Social Media in Tourism. J Tour Hosp. 2013;

4. Pateli A, Mylonas N, Spyrou A. Organizational adoption of social media in the hospitality industry: An integrated approach based on DIT and TOE frameworks. Sustain. 2020;12(17).

5. We Are Social, HootSuite. Digital 2021. 2021;

6. Guo C, Saxton GD. Tweeting Social Change: How Social Media Are Changing Nonprofit Advocacy. Nonprofit Volunt Sect Q. 2014; 
7. Lovejoy K, Waters RD, Saxton GD. Engaging stakeholders through Twitter: How nonprofit organizations are getting more out of 140 characters or less. Public Relat Rev. 2012;

8. Zachos G, Paraskevopoulou-Kollia EA, Anagnostopoulos I. Social media use in higher education: A review. Educ Sci. 2018;8(4).

9. Horhota M, Asman J, Stratton JP, Halfacre AC. Identifying behavioral barriers to campus sustainability: A multi-method approach. Int J Sustain High Educ. 2014;

10. Carpenter S, Takahashi B, Cunningham C, Lertpratchya AP. The roles of social media in promoting sustainability in higher education. Int J Commun. 2016;10:486381.
11. Mustakim M, Rahamma T, Muhammad D. Pemanfaatan Forum Komunikasi Komite Sekolah Dalam Peningkatan Mutu Pendidikan Sma Di Kabupaten Gowa. 2016;2(3):285-94.

12. Kurniawan $W$, Suprianto $A$, Sumardiyono B. Rancangan Sistem Forum Diskusi Online Untuk Program Studi Sistem Informasi Antara Dosen Dan Mahasiswa. J Rekayasa Inf. 2016;5(2):43-51.

13. Rani, Ahmad D. Implementasi Forum Alumni Pondok Pesantren As-Shiddiqiyah Berbasis Web. Jumantaka [Internet]. 2018;02(01):10. Available from: http://jurnal.stmikdci.ac.id/index.php/jumika/\%0Ahttp://lp pm.stmik-dci.ac.id 